Supporting Information for:

\title{
Substituent Controlled Framework Transformation Based on Solvent-Assisted Linker Exchange
}

Li-Hui Cao, ${ }^{*}$ Yan Yang, Xiao-Han Tang, Xu Wang, and Zheng Yin

Shaanxi Key Laboratory of Chemical Additives for Industry, College of Chemistry and Chemical Engineering, Shaanxi University of Science and Technology, Xi'an, 710021, China

*E-mail: caolihui @ sust.edu.cn

\begin{tabular}{|l|l|}
\hline \multicolumn{2}{|c|}{ Table of Contents } \\
\hline Section S1. Experimental details. & Page S2 \\
\hline Section S2. ${ }^{1}$ H NMR measurements. & Page S6 \\
\hline Section S3. Powder X-ray diffraction data. & Page S10 \\
\hline Section S4. Thermogravimetric analysis data. & Page S11 \\
\hline Section S5. Gas adsorption. & Page S12 \\
\hline Section S6. References. & Page S13 \\
\hline
\end{tabular}


Section S1. Experimental details.

Materials. All of the materials for syntheses were obtained commercially and used without further purification. All the solvents used were of analytical grade.

Instrumentation. ${ }^{1} \mathrm{H}$ NMR spectra were collected on a Bruker AVANCE III HD 400 $\mathrm{MHz}$ spectrometer. Powder X-ray diffraction patterns for capillary-encapsulated samples were obtained at room temperature with a Bruker MX I $\mu \mathrm{S}$ microsource $(\mathrm{Cu}-$ K $\alpha$ radiation) and ApexII CCD detector. TG analyses of the compounds were performed on a SDT 2960 thermal analyzer from room temperature to $800{ }^{\circ} \mathrm{C}$ at a heating rate of $10{ }^{\circ} \mathrm{C} / \mathrm{min}$ under air atmosphere. Infrared spectra (IR) were recorded on a Bruker TENSOR 27 FT-IR spectrometer in the $4000 \sim 400 \mathrm{~cm}^{-1}$ region with $\mathrm{KBr}$ pellets. $\mathrm{CO}_{2}$ sorption isotherms were collected on a Micromeritics ASAP 2020.

Ligand Synthesis. The ligands used in this work are shown in Scheme S1. The ligands of $\mathrm{H}_{2} \mathrm{~L}_{\mathrm{a}}, \mathrm{H}_{2} \mathrm{~L}_{\mathrm{b}}$ and $\mathrm{H}_{2} \mathrm{~L}_{\mathrm{c}}$ were synthesized according to the literature ${ }^{[\mathrm{S} 1-\mathrm{S} 2]}$. The ligands of $\mathrm{H}_{2} \mathrm{~L}_{\mathrm{d}}$ and $\mathrm{H}_{2} \mathrm{~L}_{\mathrm{e}}$ were obtained commercially and used without further purification.

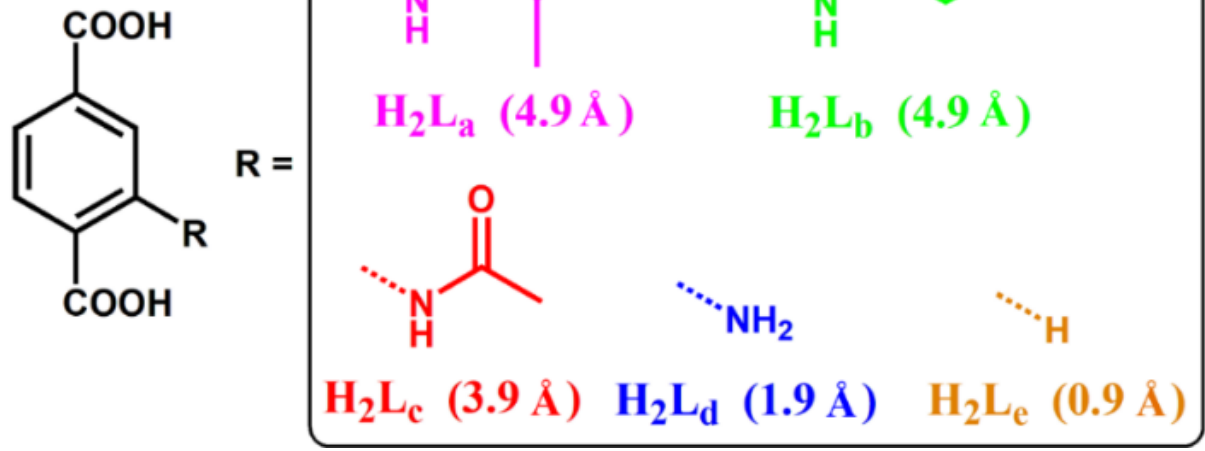

Scheme S1. The ligands of $p$-phenyldicarboxylic acid derivatives used in this work. 
Synthesis of parent material $\left\{\left[\mathrm{Cd}_{3} \mathrm{~L}_{\mathbf{a}}(\mathbf{b p y})\right] \cdot \mathbf{5 D M A} \cdot \mathbf{1 5 H}_{\mathbf{2}} \mathrm{O}\right\}_{\boldsymbol{n}}(\mathbf{1}) \cdot \mathrm{H}_{2} \mathrm{~L}_{\mathrm{a}}(20 \mathrm{mg}, 0.067$ $\mathrm{mmol}), \mathrm{Cd}\left(\mathrm{NO}_{3}\right)_{2} \cdot 4 \mathrm{H}_{2} \mathrm{O}(20 \mathrm{mg}, 0.065 \mathrm{mmol})$, and bpy (10 mg, $\left.0.064 \mathrm{mmol}\right)$ were dissolved in a mixture of DMA and methanol $(2: 1,3 \mathrm{~mL})$ in a Teflon-lined stainless steel vessel $(25 \mathrm{~mL})$. The solution was heated in an oven at $100{ }^{\circ} \mathrm{C}$ for 72 hours, and then cooled to room temperature. Colorless block crystals of complex $\mathbf{1}$ which were suitable for single-crystal X-ray analysis were obtained by filtration. The obtained crystals were washed with fresh DMA, dried in air.

FT-IR (KBr pellet, v/cm ${ }^{-1}$ ): 3500 (s), 3100 (m), 2930 (m), 1980 (w), 1756 (m), 1602 (vs), 1590 (vs), 1498 (vs), 1350 (s), 1390 (s), $1235(\mathrm{~m}), 1150$ (m), 1050 (m), 1021 (s), $953(\mathrm{w}), 821(\mathrm{w}), 801(\mathrm{~m}), 760(\mathrm{~m}), 742(\mathrm{~m}), 621(\mathrm{~m}), 605(\mathrm{~m})$.

Synthesis of complex 2 via SALE: Crystals of complex 1 were dried on a filter paper (20 mg, $0.062 \mathrm{mmol}$ ) and placed in a 2-dram screw cap vial, and a DMF solution (2 $\mathrm{mL})$ of $\mathrm{H}_{2} \mathrm{~L}_{b}(30 \mathrm{mg}, 0.13 \mathrm{mmol})$ was added. The vial was capped and placed in an isothermal oven at $100{ }^{\circ} \mathrm{C}$ for 72 hours, and then cooled to room temperature. The product was thoroughly washed with fresh DMF, dried in air.

FT-IR (KBr pellet, v/cm-1): 3445 (w), 3050 (w), 2932 (w), 1667 (vs), 1562 (s), 1509 (s), $1413(\mathrm{~s}), 1358(\mathrm{~s}), 1295(\mathrm{w}), 1251(\mathrm{~m}), 1218(\mathrm{~m}), 1100(\mathrm{~m}), 1006(\mathrm{w}), 955(\mathrm{w}), 917$ (w), $806(\mathrm{~m}), 780(\mathrm{~m}), 725(\mathrm{w}), 662(\mathrm{w}), 626(\mathrm{w}), 498(\mathrm{w})$.

Synthesis of complex 3 via SALE: The same procedure as that for complex 2 except for $\mathrm{H}_{2} \mathrm{~L}_{\mathrm{c}}(30 \mathrm{mg}, 0.13 \mathrm{mmol})$ was used instead of $\mathrm{H}_{2} \mathrm{~L}_{b}$. 
FT-IR (KBr pellet, v/cm ${ }^{-1}$ ): 3502 (w), 3051 (w), 2930 (w), 1669 (vs), 1570 (s), 1511 (m), 1413 (s), 1357 (s), 1301 (w), 1246 (m), 1098 (m), 1007 (w), 965 (w), $912(\mathrm{w}), 808$ (m), $775(\mathrm{~m}), 727(\mathrm{w}), 662(\mathrm{w}), 626(\mathrm{~m}), 554(\mathrm{w}), 499(\mathrm{~m})$.

Synthesis of complex 4 via SALE: The same procedure as that for complex 2 except for $\mathrm{H}_{2} \mathrm{~L}_{d}(30 \mathrm{mg}, 0.16 \mathrm{mmol})$ was used instead of $\mathrm{H}_{2} \mathrm{~L}_{b}$.

FT-IR (KBr pellet, v/cm ${ }^{-1}$ ): 3432 (m), 3051 (w), 2931 (w), 1664 (s), 1607 (m), 1560 (s), $1415(\mathrm{~m}), 1366$ (m), 1251 (m), $1222(\mathrm{w}), 1099$ (w), 957 (w), $810(\mathrm{~m}), 776(\mathrm{~m}), 729(\mathrm{w})$, $662(\mathrm{w}), 627(\mathrm{w}), 570(\mathrm{w}), 490(\mathrm{w})$.

Synthesis of complex 5 via SALE: Crystals of complex 1 were dried on a filter paper (20 mg, $0.062 \mathrm{mmol}$ ) and placed in a 2-dram screw cap vial, and a DMA solution (2 $\mathrm{mL})$ of $\mathrm{H}_{2} \mathrm{~L}_{\mathrm{e}}(30 \mathrm{mg}, 0.18 \mathrm{mmol})$ was added. The vial was capped and placed in an isothermal oven at $100{ }^{\circ} \mathrm{C}$ for 24 hours, and then cooled to room temperature. The product was thoroughly washed with fresh DMA, dried in air.

FT-IR (KBr pellet, v/cm ${ }^{-1}$ ): 3452 (w), 3050 (w), 2936 (w), 1942 (w), 1740 (m), 1602 (vs), 1507 (s). 1379 (vs), 1299 (w), 1225 (m), 1188 (w), 1075 (m), 1012 (m), 958 (w), $917(\mathrm{w}), 812(\mathrm{~s}), 778(\mathrm{w}), 744(\mathrm{~m}), 627(\mathrm{~m}), 596(\mathrm{w}), 496(\mathrm{~m})$.

Synthesis of complex 6 via SALE or structural transformation: The same procedure as that for complex 5 except for the reaction time was increased to 48 hours. The product 6 was thoroughly washed with fresh DMA, dried in air. The as-synthesized complex 5 was placed in the air for 24 hours, complex $\mathbf{6}$ can also be obtained. 
FT-IR (KBr pellet, v/cm ${ }^{-1}$ ): 3476 (w), 3050 (w), 2935 (w), 1942 (w), 1739 (w), 1577 (vs), 1501 (m), 1385 (vs), $1260(\mathrm{w}), 1219$ (m), $1186(\mathrm{w}), 1073(\mathrm{w}), 1011(\mathrm{~m}), 960(\mathrm{w})$, $886(\mathrm{w}), 813(\mathrm{~s}), 744(\mathrm{~s}), 627(\mathrm{~m}), 595(\mathrm{~m}), 497(\mathrm{~m})$. 


\section{Section S2. ${ }^{1} \mathrm{H}$ NMR measurements.}

Approximately $5 \mathrm{mg}$ of samples were placed in a 1.5-dram vial containing deuterated dimethyl sulfoxide (DMSO). 2 drops of $\mathrm{D}_{2} \mathrm{SO}_{4}$ were added and the crystals were sonicated to achieve complete dissolution. The sample was then transferred to an NMR tube. The ${ }^{1} \mathrm{H}$ NMR spectra were obtained by locking to DMSO.

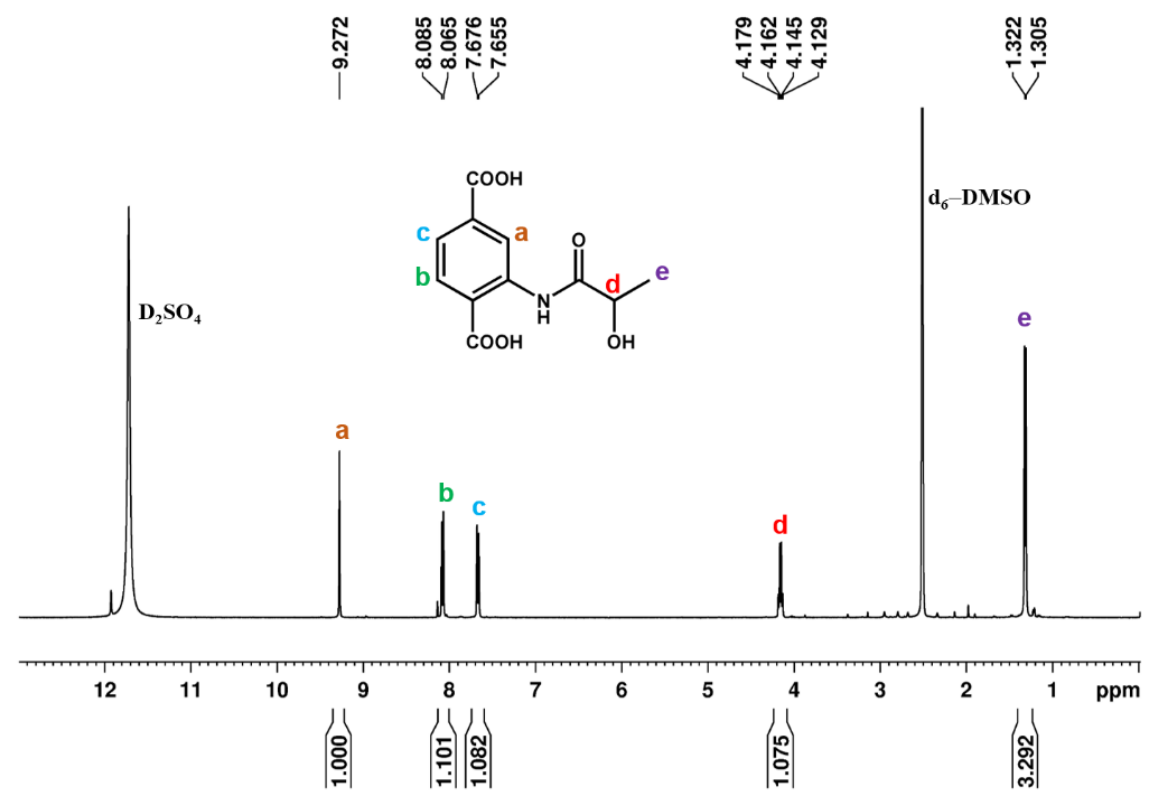

Figure S1. The ${ }^{1} \mathrm{H}$ NMR spectrum of $\mathrm{H}_{2} \mathrm{~L}_{\mathrm{a}}$. 


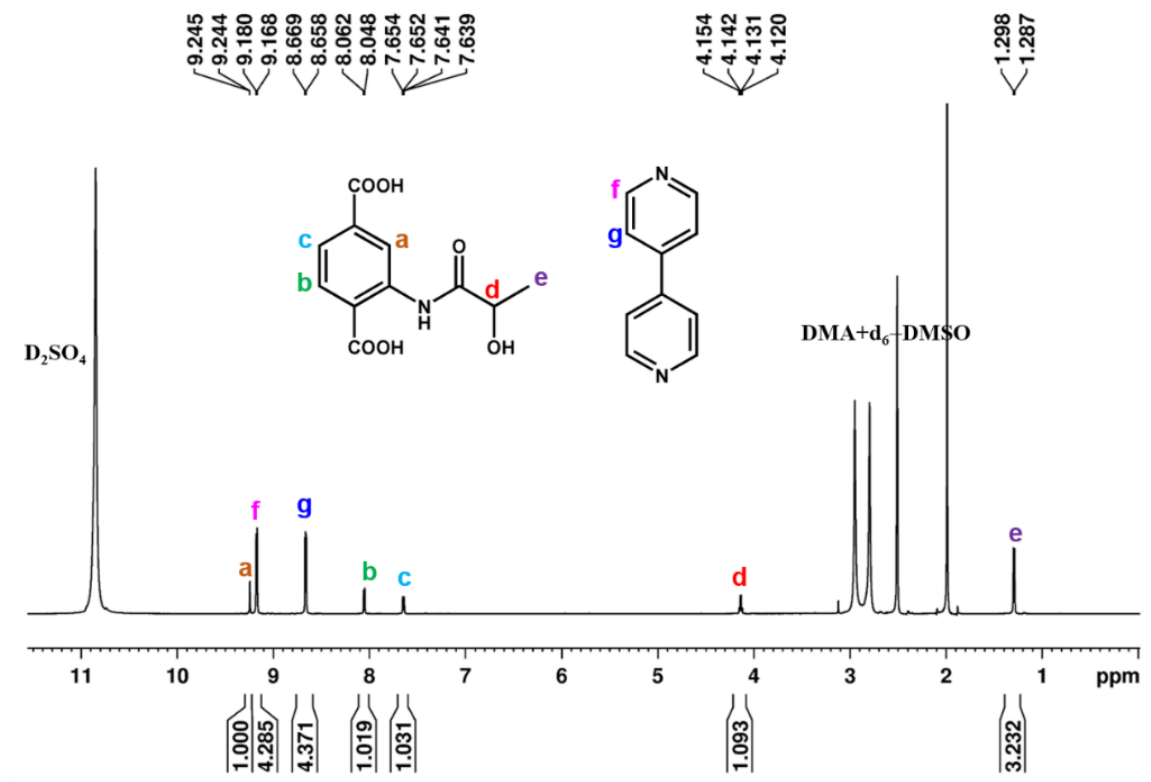

Figure S2. The ${ }^{1} \mathrm{H}$ NMR spectrum of complex 1 .

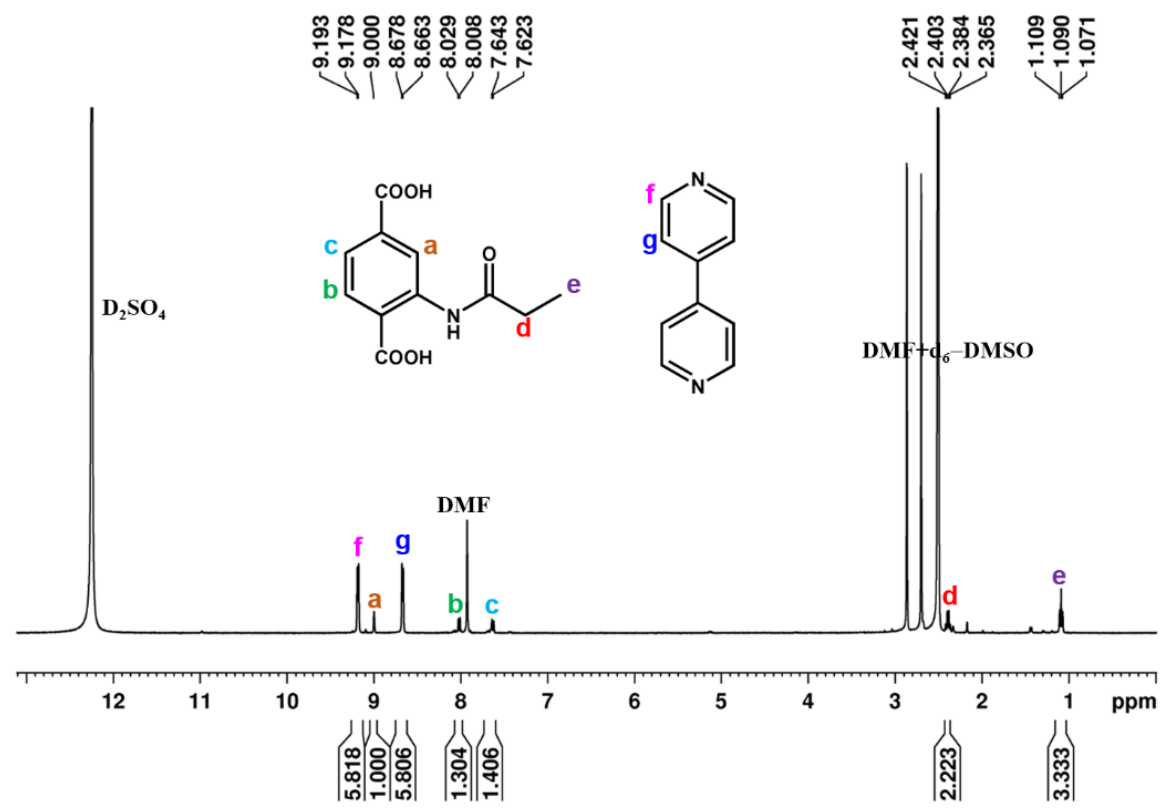

Figure S3. The ${ }^{1} \mathrm{H}$ NMR spectrum of complex 2. 


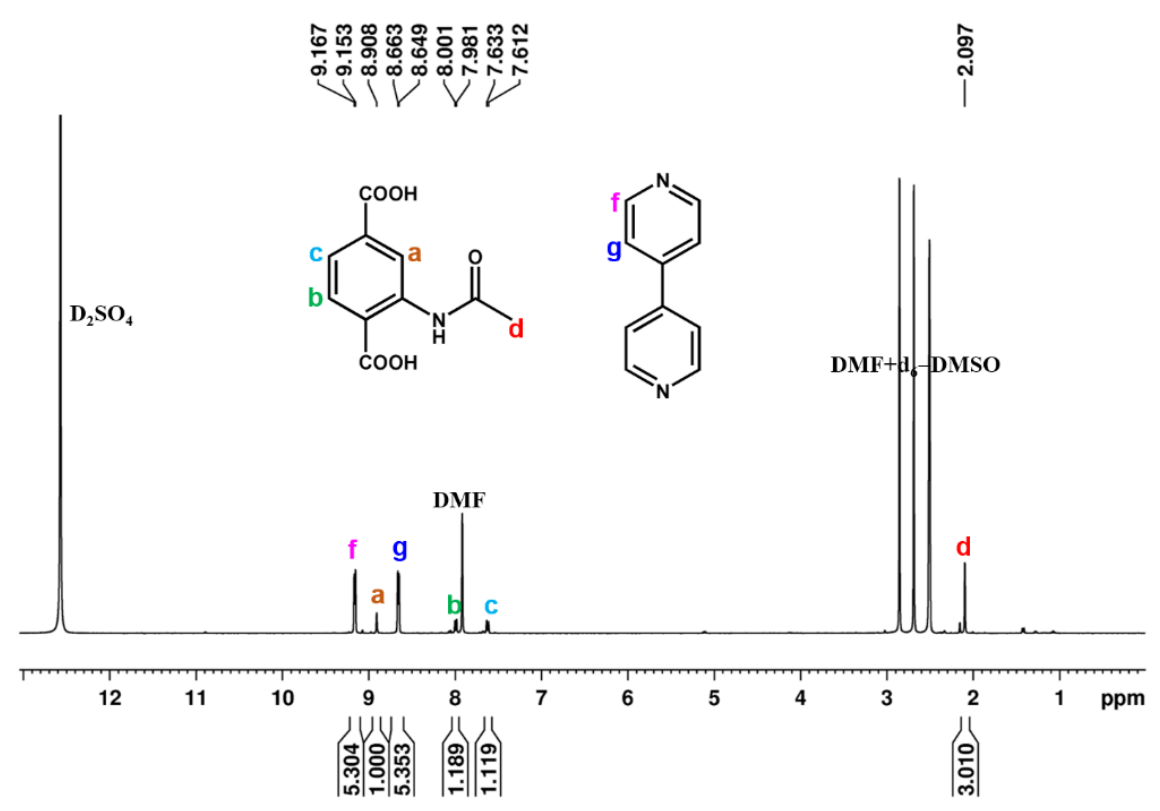

Figure S4. The ${ }^{1} \mathrm{H}$ NMR spectrum of complex 3 .

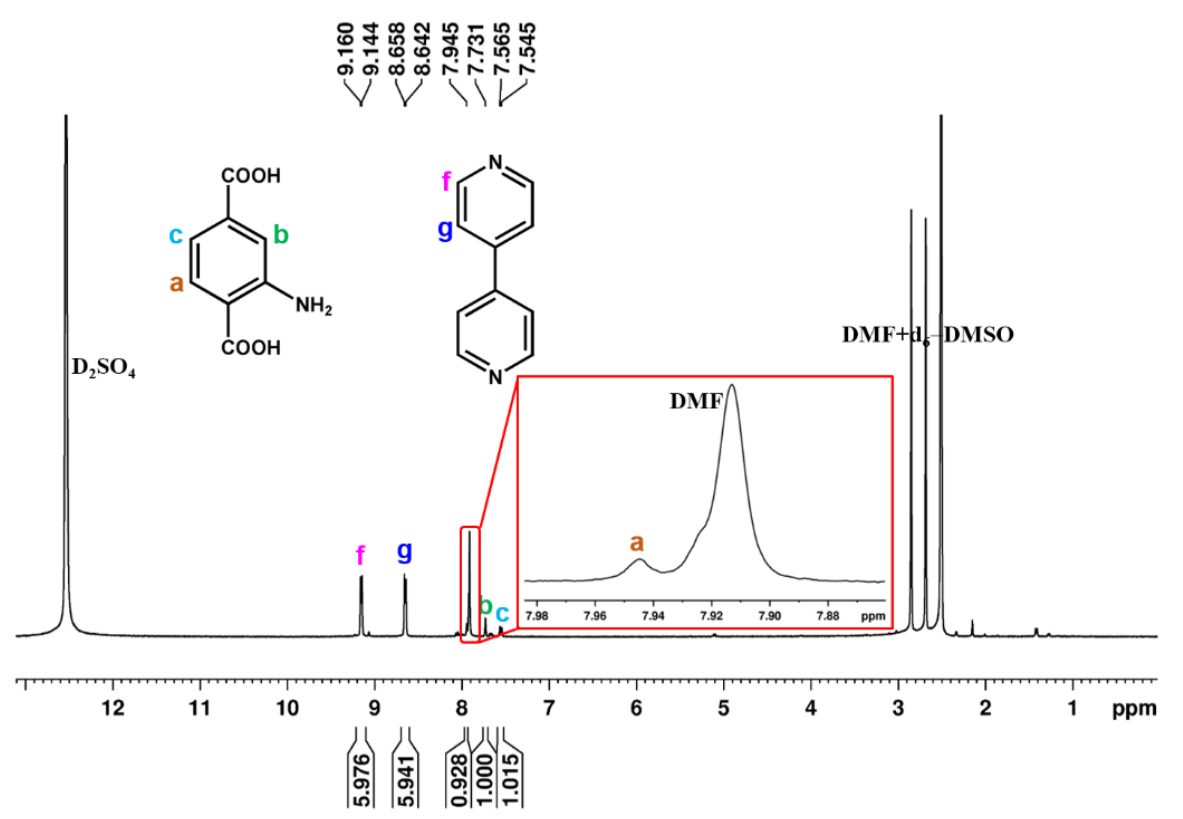

Figure S5. The ${ }^{1} \mathrm{H}$ NMR spectrum of complex 4 . 


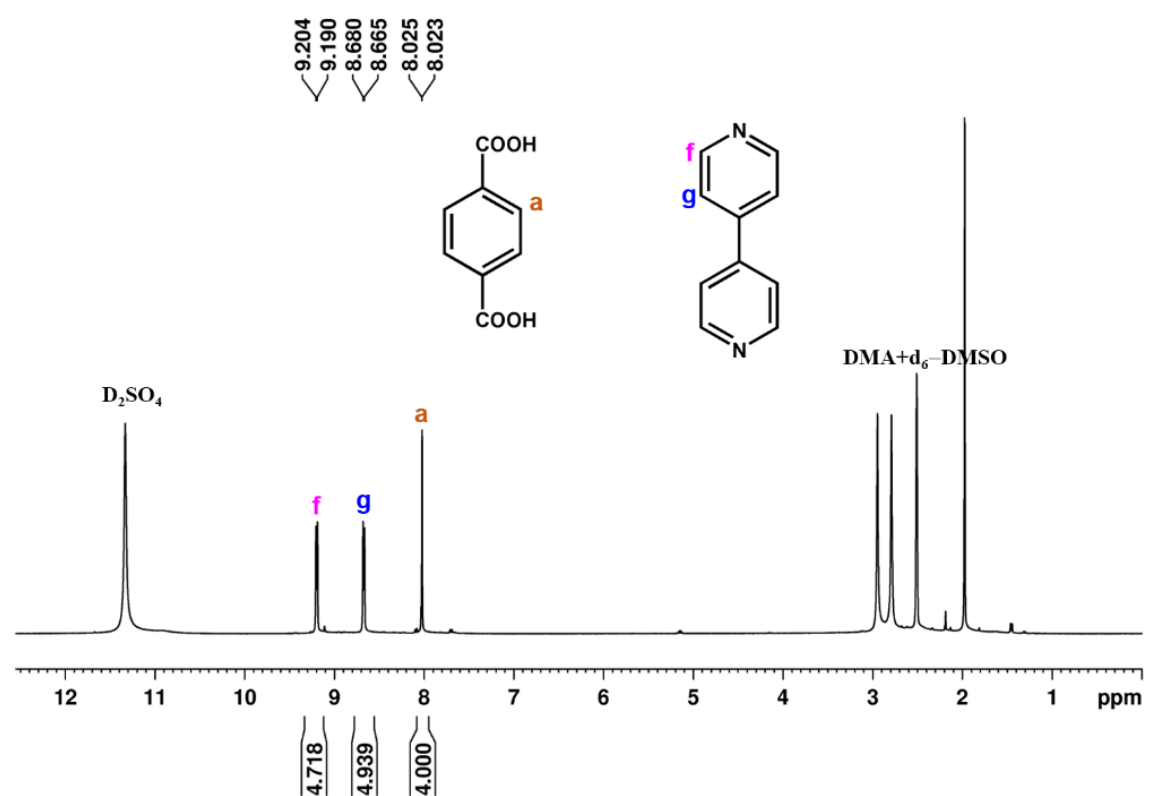

Figure S6. The ${ }^{1} \mathrm{H}$ NMR spectrum of complex 5.

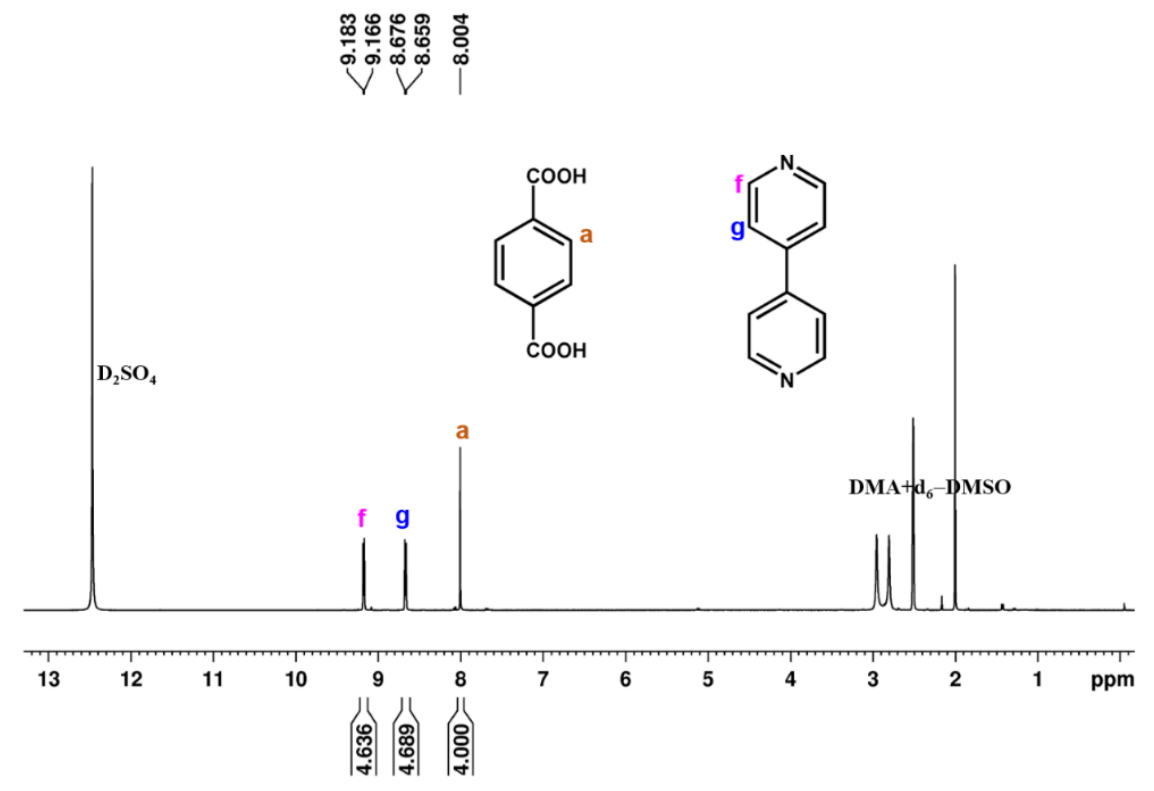

Figure S7. The ${ }^{1} \mathrm{H}$ NMR spectrum of complex 6. 
Section S3. Powder X-ray diffraction data.

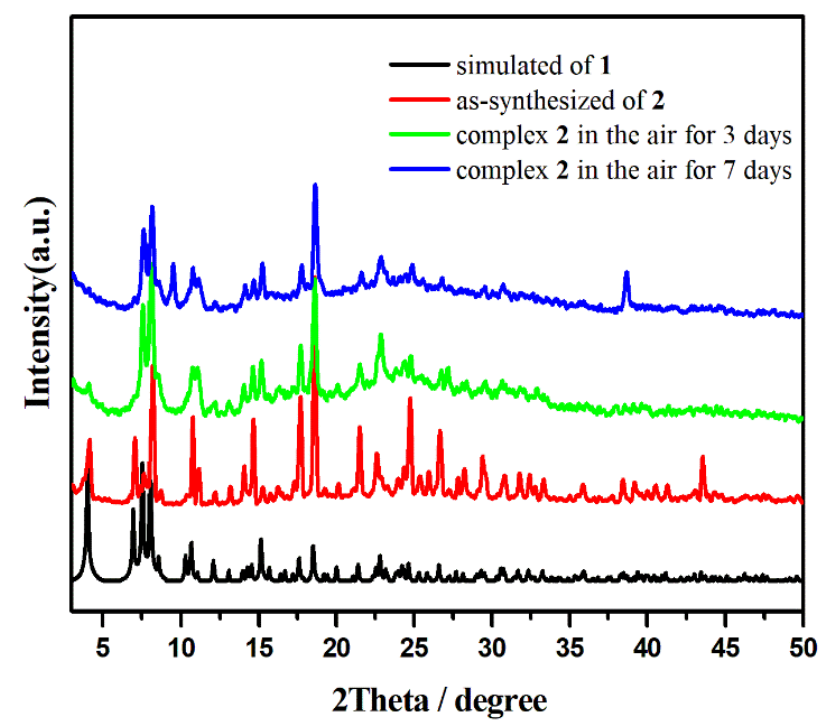

Figure S8. PXRD patterns of complex 2 placed in air for 7 days to confirm the stability of framework.

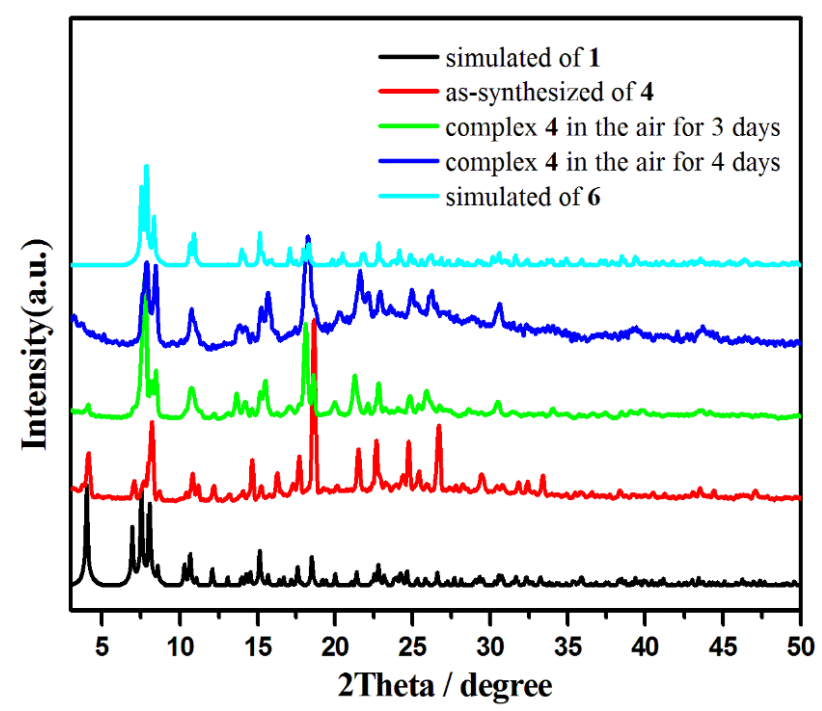

Figure S9. PXRD patterns of complex 4 placed in air for 4 days to confirm the spontaneous structural transformations. 
Section S4. Thermogravimetric analysis data.

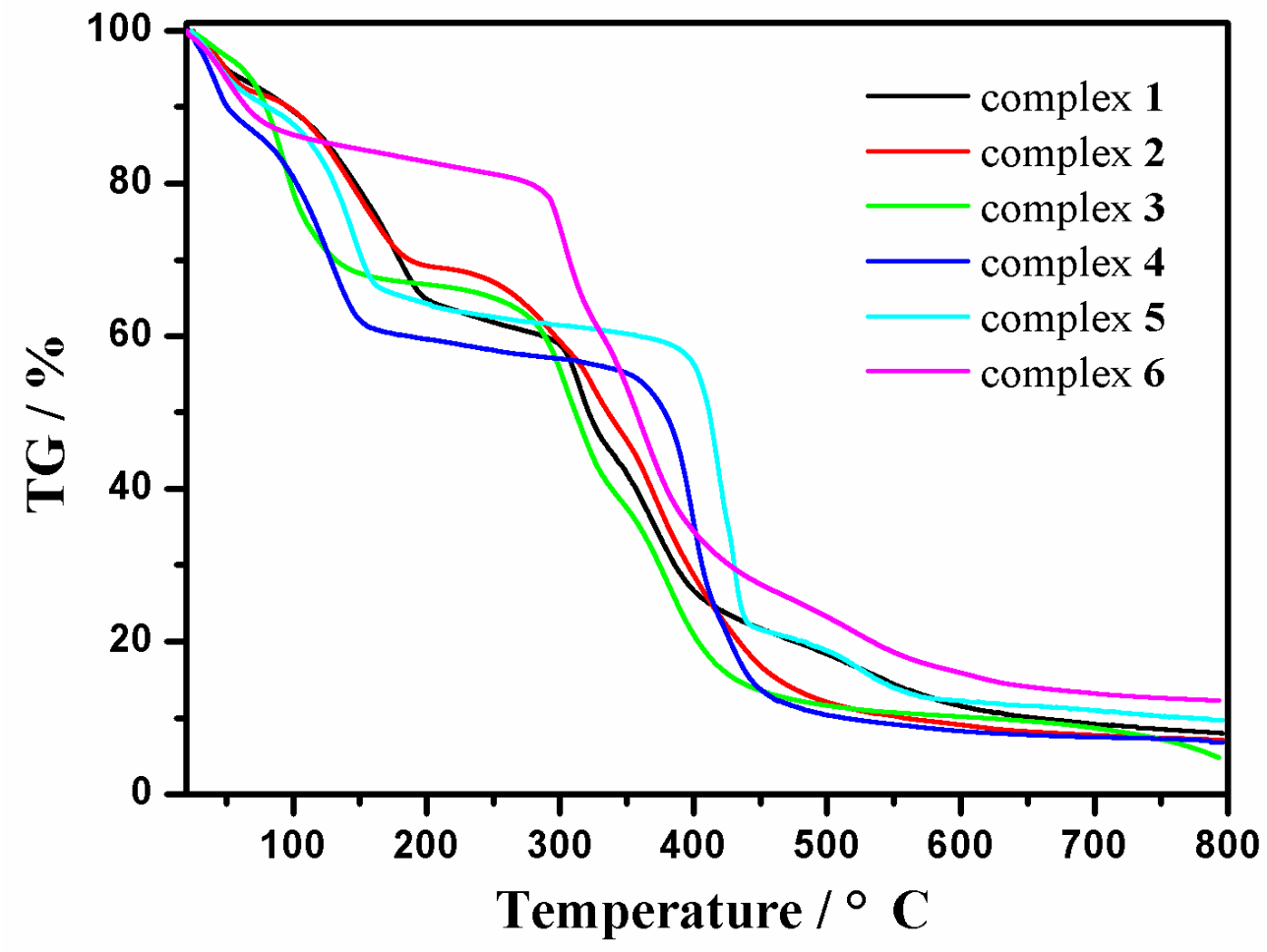

Figure S10. The TGA curves of complexes 1-6. 
Section S5. Gas adsorption.

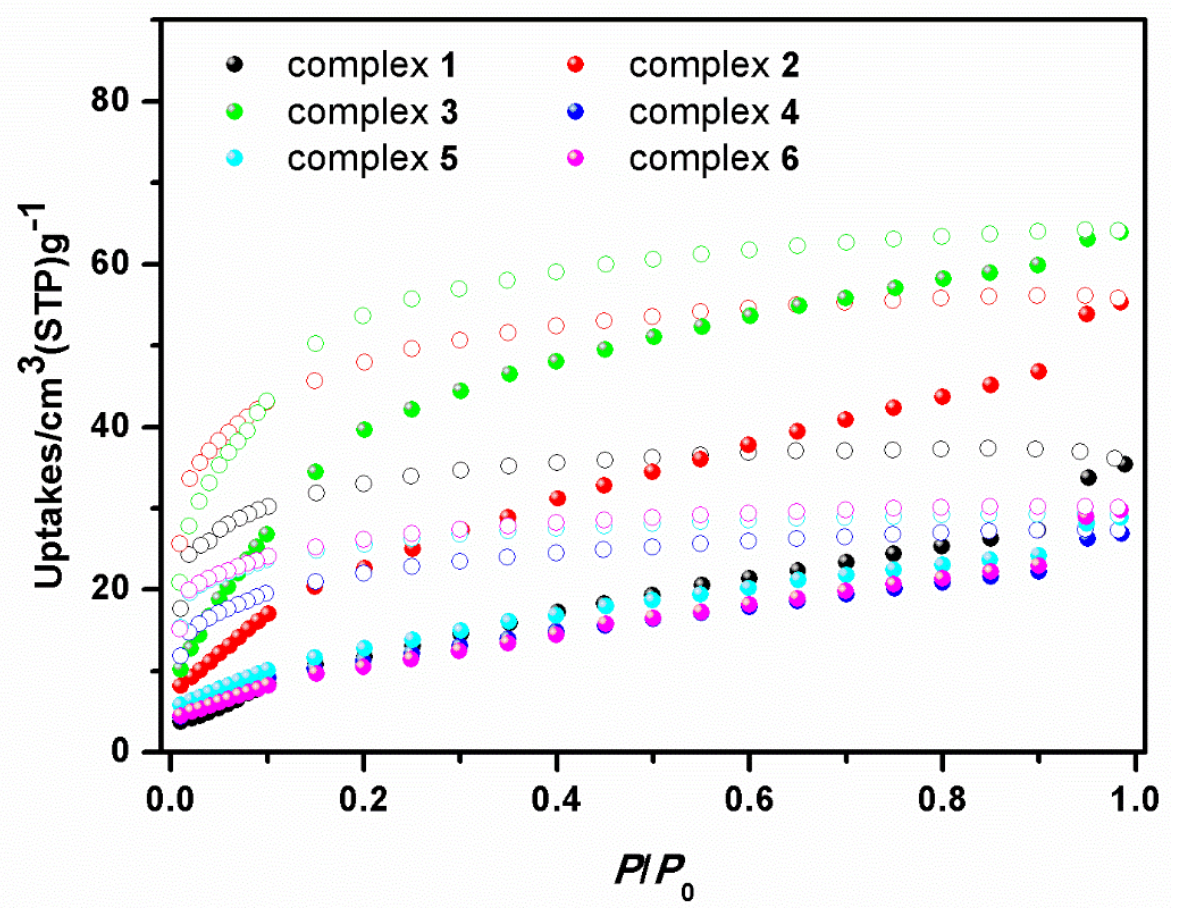

Figure S11. $\mathrm{CO}_{2}$ absorption (solid) and desorption (hollow) isotherms of complexes 1-6 at $195 \mathrm{~K}$. 
Section S6. References.

[S1] Cao, L.-H.; Wei, Y.-S.; Xu, H.; Zang, S.-Q.; Mak, T. C. W. Unveiling the Mechanism of Water-Triggered Diplex Transformation and Correlating the Changes in Structures and Separation Properties. Adv. Funct. Mater. 2015, 25, $6448-6457$.

[S2] Karmakar, A.; Guedes da Silva, M. F. C.; Pombeiro, A. J. L. Zinc Metal-Organic Frameworks: Efficient Catalysts for the Diastereoselective Henry Reaction and Transesterification, Dalton Trans. 2014, 43, 7795-7810. 